Check for updates

Cite this: Phys. Chem. Chem. Phys., 2019, 21, 15615

\section{Quantifying electronic similarities between NHC-gold(I) complexes and their isolobal imidazolium precursors $\dagger$}

\author{
Luis Miguel Azofra, (D) *ab Richard M. P. Veenboer, (D) ${ }^{c}$ Laura Falivene, $^{d}$ \\ Sai V. C. Vummaleti, (iD ${ }^{d}$ Albert Poater, (D) e Steven P. Nolan (D) $*^{f g}$ and \\ Luigi Cavallo id *d
}

\begin{abstract}
A series of $\mathrm{NHC}$-gold( () ( $\mathrm{NHC}=\mathrm{N}$-heterocyclic carbene) complexes has been studied by DFT calculations, enabling comparison of electronic and NMR behaviour with related protonated and free NHC molecules. Based on calculations, the NMR resonances of the carbenic $\mathrm{C}^{2}$ carbon atom in $[\mathrm{Au}(\mathrm{NHC})(\mathrm{Cl})]$ and $[\mathrm{NHC}(\mathrm{H})][\mathrm{Cl}]$ exhibit increased shielding when compared to the free $\mathrm{N}$-heterocyclic carbenes by an average of $46.6 \pm 2.2$ and $73.7 \pm 4.3$ ppm, respectively. A similar trend is observed when analysing the paramagnetic term of the magnetic shielding tensor. Although gold $(I)$ and proton are considered isolobal fragments, imidazolium compounds lack $\pi$-backdonation due to the energetic unavailability of d-orbitals in $\mathrm{H}^{+}$. We propose that $\mathrm{NHC}$-gold(I) complexes exhibit important $\pi$-backdonation irrespective of the relative amount of $\sigma$-donation between the $\mathrm{NHC}$ and gold $(\mathrm{I})-\mathrm{X}(\mathrm{X}=$ anionic ligand) moieties in $\mathrm{Au}-\mathrm{NHC}$ complexes. Interestingly, a correlation exists between the calculated shielding for gold $\left({ }^{197} \mathrm{Au}\right)$ and the $\pi$-donation and $\pi$-backdonation contributions. We describe that this correlation also exists when analysing the $\sigma$-backdonation term, a property generally ignored yet representing a significant energetic contribution

to the stability of the $\mathrm{C}^{2}-\mathrm{Au}$ bond.
\end{abstract}

Accepted 26th June 2019

DOI: $10.1039 / c 9 c p 02844 g$

rsc.li/pccp

\section{Introduction}

The isolation and structural determination of the first persistent free N-heterocyclic carbene (NHC) by Arduengo and coworkers ${ }^{1}$ in 1991 certainly constitutes a milestone in the field of synthetic organic chemistry. However, two decades prior to this

\footnotetext{
${ }^{a}$ CIDIA-FEAM (Unidad Asociada al Consejo Superior de Investigaciones Cientificas, CSIC, avalada por el Instituto de Ciencia de Materiales de Sevilla, Universidad de Sevilla), Instituto de Estudios Ambientales y Recursos Naturales (i-UNAT), Universidad de Las Palmas de Gran Canaria (ULPGC), Campus de Tafira, 35017, Las Palmas de Gran Canaria, Spain. E-mail: luismiguel.azofra@ulpgc.es

${ }^{b}$ Departamento de Química, Universidad de Las Palmas de Gran Canaria (ULPGC), Campus de Tafira, 35017, Las Palmas de Gran Canaria, Spain

${ }^{c}$ EaStCHEM, School of Chemistry, University of St Andrews, North Haugh, St Andrews, KY16 9ST, UK

${ }^{d}$ King Abdullah University of Science and Technology (KAUST), KAUST Catalysis Center (KCC), Thuwal 23955-6900, Saudi Arabia.

E-mail: luigi.cavallo@kaust.edu.sa

${ }^{e}$ Institut de Química Computacional i Catàlisi, Departament de Química, Universitat de Girona, c/M $M^{a}$ Aurèlia Capmany 69, 17003 Girona, Catalonia, Spain ${ }^{f}$ Department of Chemistry and Center for Sustainable Chemistry, Ghent University, Building S3, Krijgslaan 281, 9000 Gent, Belgium.E-mail: Steven.Nolan@ugent.be

${ }^{g}$ Department of Chemistry, College of Science, King Saud University, P.O. Box 2455, Riyadh 11451, Saudi Arabia

$\dagger$ Electronic supplementary information (ESI) available: Computational details and all XYZ coordinates of all species. See DOI: 10.1039/c9cp02844g
}

seminal contribution, NHCs had already been identified as potential ligands in organometallic complexes of mercury ${ }^{2}$ and chromium. ${ }^{3}$ In this context, the important $\sigma$-donor ability of the carbene lone pair enabled the formation of NHC-metal complexes prior to the synthesis of the first isolable carbene whose stability as a stand-alone entity greatly depends on electronic and steric properties of the organic decorating groups around the imidazole framework.

With the disclosure of a synthetic access to the N-heterocyclic carbenes by Arduengo, ${ }^{1}$ rich organometallic chemistry and homogeneous catalysis have emerged to take advantage of the unique steric and electronic properties of this ligand class. ${ }^{4-8}$ The impact of this chemistry cannot be overstated as is evident from the vast metal-NHC literature. ${ }^{9-15}$

Although the first bis(carbene) complexes of gold(I) and gold(III) were isolated in $1973,{ }^{16}$ it was only several decades later that the chemistry of gold-NHC complexes found renewed interest and was applied to catalytic transformations such as the protodecarboxylation of (hetero)aromatic carboxylic acids, ${ }^{17}$ the synthesis of lactones by cyclisation of alkynoic acids, ${ }^{18}$ the hydrophenoxylation ${ }^{19}$ and hydroalkoxylation ${ }^{20}$ of alkynes, functionalization of terminal alkynes and alkenes, ${ }^{21}$ or direct arene $\mathrm{C}-\mathrm{H}$ bond functionalization, ${ }^{22}$ amongst other applications such as their use as anticancer drugs. ${ }^{23-25}$ 
Key to these advances is a fundamental understanding of the gold-carbon bond. In the present study we address the electronic properties characterising the gold-carbene carbon bond.

Contrary to the generally accepted hypothesis that transition metal complexes bearing NHC ligands were solely supported by $\mathrm{NHC} \rightarrow \mathrm{M}(\mathrm{M}=$ metal $) \sigma$-donation, it has been shown that the carbene carbon-metal bond is also stabilised by $\mathrm{M} \rightarrow$ NHC $\pi$-backdonation. ${ }^{26}$ This interaction, which involves the occupied and empty $\mathrm{d}$ - and p-like orbitals in the $\mathrm{M}$ and carbene carbon atoms, respectively, has been calculated to represent $c a$. 10-25\% of the total interaction energy for a representative group of NHCmetal models in which $\mathrm{M}$ can be any transition metal of groups 4, 6, 8, 10 and $11 .^{27} \pi$-Backdonation cannot be considered a negligible component in the overall NHC-M bonding picture. ${ }^{28}$

The $\pi$-backdonation component in complexes bearing $\mathrm{NHC}$ ligands has been assessed via various methods, that is, a series of changes in fundamental physicochemical properties has been described to correlate with the $\pi$-accepting ability. For example, Nolan and Cavallo ${ }^{29}$ made use of ${ }^{1} J_{\mathrm{Pt}-\mathrm{C}}$ coupling constants in $\left[\mathrm{PtCl}_{2}(\mathrm{DMSO})(\mathrm{NHC})\right]$ complexes and more recently Belpassi and co-workers $^{30}$ examined this relation analysing changes in the $\mathrm{C} \equiv \mathrm{O}$ vibrational stretching mode for $[\mathrm{Au}(\mathrm{NHC})(\mathrm{CO})]^{+}$adducts. In a more closely related approach to the current investigation, Bertrand $^{31}$ and Ganter ${ }^{32}$ separately studied the effect of the $\pi$-backdonation component by analysis of ${ }^{31} \mathrm{P}$ and ${ }^{77} \mathrm{Se}$ NMR spectroscopy in phosphinidenes and selenoureas, respectively.

In the present report, with the aim of understanding the electronic and NMR properties of a set of gold(I)-NHC complexes, we examine, using DFT, well-defined complexes and compare them with their isolobal imidazolium and free NHC relatives. Amongst our objectives is the analysis of the main components of the shielding and the orbital transitions propitiated by application of a magnetic field. Furthermore, we also account for the $\sigma$ and $\pi$ donor/acceptor properties that stabilise the carbene carbon-gold bond. ${ }^{33}$ These contributions that are not manifested by changes in ${ }^{13} \mathrm{C}^{2}$ spectroscopic data, but they are related by ${ }^{197} \mathrm{Au} \mathrm{NMR}$ analysis.

\section{Computational details}

The structures and energies for a set of NHC-gold(I) (NHC = $\mathrm{N}$-heterocyclic carbene) and their isolobal imidazolium salts and free NHCs have been studied with Density Functional Theory (DFT) via the spin-restricted Kohn-Sham (RKS) formalism. The Generalised Gradient Approximation (GGA) has been used via the BP86 functional ${ }^{34,35}$ together with the TZ2P Slater-Type Orbital (STO) basis set, ${ }^{36}$ which is augmented by one polarisation function for both light (hydrogen) and heavy atoms. The DIIS procedure was applied for the Self-Consistent Field (SCF) convergence with the Becke fuzzy cells integration scheme (quality good). ${ }^{37,38}$ Optimisations have been carried out without any symmetry constrain.

The Zeroth Order Regular Approximation (ZORA) $)^{39-41}$ to the Dirac equation was applied during the optimisation calculations in the gas phase in order to include relativistic effects (scalar) with frozen inner-core orbitals. Nuclear Magnetic Resonance (NMR) chemical shifts were calculated using the Gauge-Including Atomic Orbitals (GIAO) method ${ }^{42-45}$ through all electrons basis set and including relativistic spin-orbit coupling.

Energy Decomposition Analysis (EDA) ${ }^{46}$ has been performed over $C_{\mathrm{s}}$-symmetrised $[\mathrm{Au}(\mathrm{NHC})(\mathrm{Cl})]$ complexes by rigid fragmentation into the NHC and AuCl moieties.

All calculations were carried out through the facilities provided by the Amsterdam Density Functional (ADF) modelling suite package (revision 2016.102). In all cases, structures have been previously evaluated at the BP86/DZP level of theory corroborating the nature of the minina, i.e., without any imaginary frequency.

\section{Results and discussion}

We start our analysis proposing a set of twenty-five $[\mathrm{Au}(\mathrm{NHC})(\mathrm{X})]$ complexes where $\mathrm{X}$ is $\mathrm{Cl}^{-}, \mathrm{OH}^{-}$or $\mathrm{CH}_{3} \mathrm{COCH}_{2}{ }^{-}$counter-anions (see Fig. 1). This set includes a wide variety of unsaturated and saturated NHCs, which are characterised to be symmetrically functionalised on their $\mathrm{N}$ atoms. The NMR properties of these well-known complexes have already been reported. ${ }^{4-56} \mathrm{~A}$ comparison between the measured and calculated chemical shifts for the carbenic carbon atom, $\delta\left({ }^{13} \mathrm{C}^{2}\right)$, displays both great similarity (slope close to 1 ) and correlation $\left(R^{2}=0.98\right)$ (see Fig. 2a). As an important methodological detail, it should be mentioned that these small divergences are only described when carrying out an all-electrons calculation (core plus valence) and include scalar and spin-orbit relativistic effects during optimisation and NMR estimations, respectively (see Table S1 in the ESI $\dagger$ for further details). Once validated, our methodology focusing on DFT data, $\delta\left({ }^{13} \mathrm{C}^{2}\right)$ spans a $38.5 \mathrm{ppm}$ range in the 173.0-211.5 ppm window (vs. TMS, with $\sigma_{\text {ref }}=185.0 \mathrm{ppm}$ ). Only taking into account $[\mathrm{Au}(\mathrm{NHC})(\mathrm{Cl})]$ adducts, these values span a range of $21.2 \mathrm{ppm}$ (174.4-195.6 ppm).

Since the relationship presented in Fig. 2a discriminates between the data corresponding to $[\mathrm{Au}(\mathrm{NHC})(\mathrm{Cl})]$ (black), $[\mathrm{Au}(\mathrm{NHC})(\mathrm{OH})]$ (red) and $\left[\mathrm{Au}(\mathrm{NHC})\left(\mathrm{CH}_{3} \mathrm{COCH}_{2}\right)\right]$ (green) complexes, chlorine and hydroxide NHC-gold(I) complexes exhibit very similar behaviour of $\delta\left({ }^{13} \mathrm{C}^{2}\right)$, not diverging by more than $3 \mathrm{ppm}$. On the other hand, the gold(I)-NHC complexes bearing auxiliary ligands containing $\mathrm{sp}^{3}$-hybridised carbon centres exhibit more shifted $\delta\left({ }^{13} \mathrm{C}^{2}\right)$ values. In this sense, the aforementioned free carbenes (Fig. 2b) display $\delta\left({ }^{13} \mathrm{C}^{2}\right)$ in a range of $27.9 \mathrm{ppm}$ in the 218.3-246.2 ppm window and the isolobal chloride NHC-proton compounds of $[\mathrm{Au}(\mathrm{NHC})(\mathrm{Cl})]$ (Fig. 2c) span $20.9 \mathrm{ppm}$ in the 146.3-167.2 ppm range. Of note, in both cases good correlations are also obtained between experimental ${ }^{51}$ and DFT calculated data with $R^{2}=0.97$ and 0.92 , respectively, even though the latter partially lacks equally distributed values.

The chemical shift of a nucleus can be expressed as $\delta_{\text {sample }}=$ $\sigma_{\text {ref }}-\sigma_{\text {sample }}$ As previously stated, tetramethylsilane, TMS, is used as a reference for the magnetic shielding, $\sigma_{\text {ref }}$. Concerning the magnetic shielding of the sample ( $\sigma_{\text {sample }}$ or just $\sigma$; not to be confused with $\sigma$-orbital symmetry) and focusing on the 

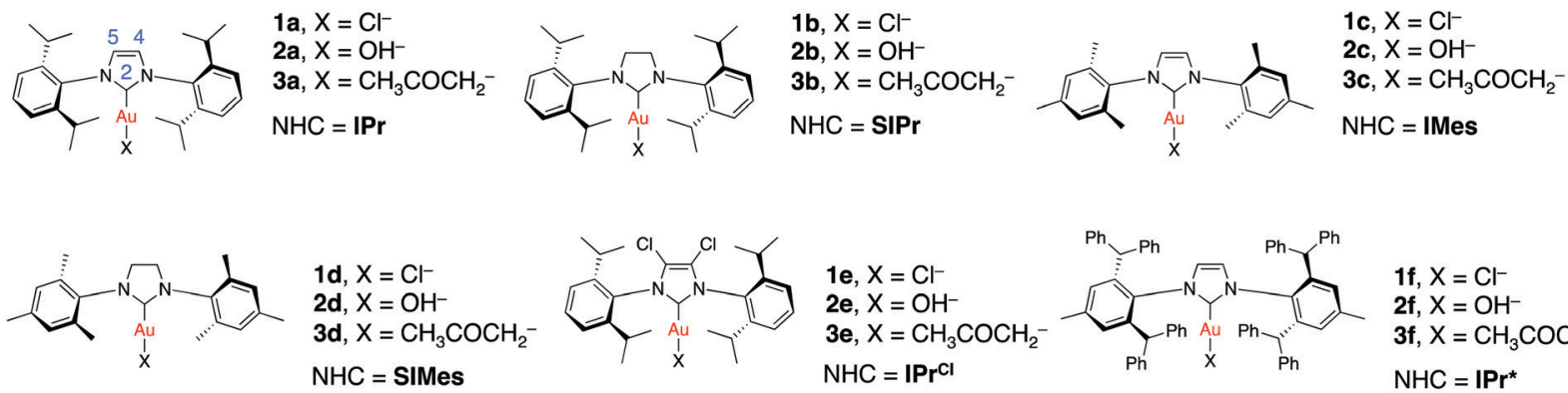

1f, $\mathrm{X}=\mathrm{Cl}$

2f, $\mathrm{X}=\mathrm{OH}^{-}$

3f, $\mathrm{X}=\mathrm{CH}_{3} \mathrm{COCH}_{2}^{-}$ $\mathrm{NHC}=\mathrm{IPrCl}$

$\mathrm{NHC}=\mathrm{IPr}^{*}$
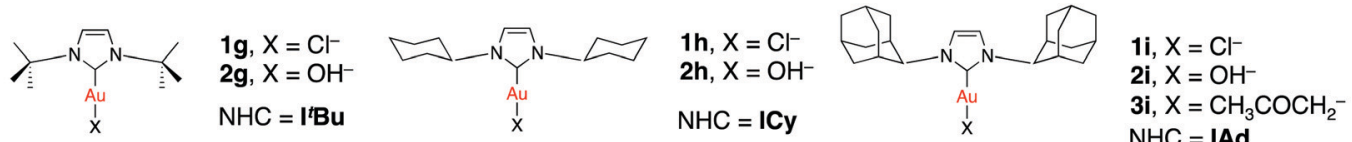

Fig. 1 Selected $[\mathrm{Au}(\mathrm{NHC})(\mathrm{X})]$ complexes $\left(\mathrm{X}=\mathrm{Cl}^{-}, \mathrm{OH}^{-}\right.$and $\left.\mathrm{CH}_{3} \mathrm{COCH}_{2}{ }^{-}\right)$previously synthesised and reported their NMR properties. Note: numbers specified at $[\mathrm{Au}(\mathrm{IPr})(\mathrm{X})]$ complex refer to the commonly accepted atomic index assignments in which carbene carbon atom is identified as $\mathrm{C}^{2}$.
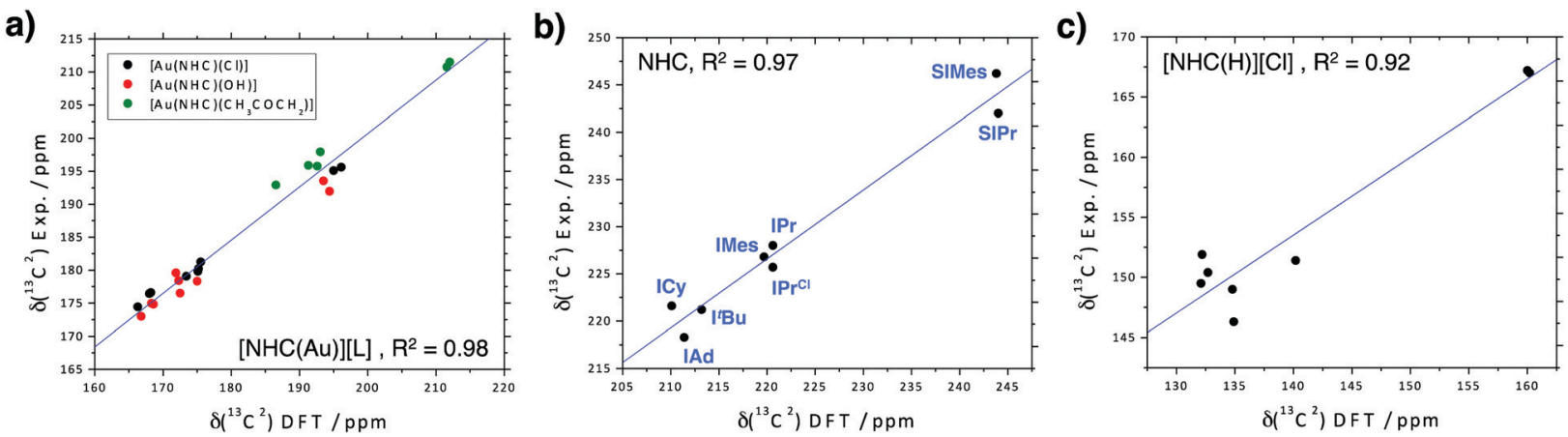

Fig. 2 Correlation plots between experimentally measured and DFT calculated $\delta\left({ }^{13} \mathrm{C}^{2}\right)$ for: (a) $[\mathrm{Au}(\mathrm{NHC})(\mathrm{X})]$ complexes, being $\mathrm{X}=\mathrm{Cl}^{-}(\mathrm{black}), \mathrm{OH}^{-}(\mathrm{red})$ and $\mathrm{CH}_{3} \mathrm{COCH}_{2}^{-}$(green); (b) free NHCs; and (c) $[\mathrm{NHC}(\mathrm{H})][\mathrm{Cl}]$ compounds. Note: using TMS as reference $\left(\sigma_{\text {ref }}=185.0 \mathrm{ppm}\right)$.

$\mathrm{C}^{2}$ nucleus, it follows that $\sigma\left({ }^{13} \mathrm{C}^{2}\right)$ is shielded (upfield) in $[\mathrm{Au}(\mathrm{NHC})(\mathrm{Cl})]$ and $[\mathrm{NHC}(\mathrm{H})][\mathrm{Cl}]$ systems because shielding increases with respect to the free NHC, that is, the nucleus in the complexes is subjected to a weaker magnetic field. This is apparent in Fig. 3a, where, for a series of nine examples (including the simplest N-heterocyclic carbene of $1 H$-imidazol-3-ium-2ide; trivial name as $\mathbf{H}), \sigma\left({ }^{13} \mathrm{C}^{2}\right)$ is shielded in an average of $46.6 \pm$ 2.2 and $73.7 \pm 4.3 \mathrm{ppm}$ for $\mathrm{NHC}-$ gold(I) and imidazolium chlorides, respectively.

On the other hand, $\sigma$ can be separated into two main contributions (three if spin-orbit relativistic effects are included): $\sigma=\sigma_{\mathrm{d}}+\sigma_{\mathrm{p}}\left(+\sigma_{\mathrm{so}}\right)$. Thus, the diamagnetic term, $\sigma_{\mathrm{d}}$, depends on unperturbed electron density in the ground state, while the paramagnetic term, $\sigma_{\mathrm{p}}$, depends on both occupied-occupied and occupied-virtual (or unoccupied orbital) couplings between molecular orbitals (MOs), induced by the external magnetic field. In all studied cases, the paramagnetic term is the one varying amongst the different compounds (see Fig. $3 \mathrm{~b}$ ), with a similar trend as the upfield shielding of $\sigma\left({ }^{13} \mathrm{C}^{2}\right)$. Specifically, $\sigma_{\mathrm{p}}\left({ }^{13} \mathrm{C}^{2}\right)$ is shielded in an average of $57.0 \pm 2.8$ and $88.0 \pm 4.5 \mathrm{ppm}$ for NHC-gold(I) complexes and imidazolium chlorides with respect to the free NHCs for the nine cases illustrated in Fig. 3b. (Note that $\sigma_{\mathrm{p}}$ is always negative, thus the more negative the more deshielded or downfield is the resonance and vice versa).
Since $\sigma_{\mathrm{p}}$ directly corresponds to the overlapping experienced by orbitals connected by symmetry when an external magnetic field is applied (Scheme 1), and at the same time, $\sigma_{\mathrm{p}}$ can be separated as the sum of contributions given by the trace of its $3 \times 3$ tensor as $\sigma_{\mathrm{p}}=\left(\sigma_{\mathrm{p}, \mathrm{Xx}}+\sigma_{\mathrm{p}, \mathrm{YY}}+\sigma_{\mathrm{p}, \mathrm{ZZ}}\right) / 3$, this allows an indepth analysis of the main components explaining why the $\mathrm{C}^{2}$ nucleus in NHC-gold(I) complexes and imidazolium compounds is shielded with regard to the free NHCs. To some extent, it also allows for the quantification of the similarity of the $\mathrm{AuCl}$ and $\mathrm{HCl}$ isolobal fragments.

Using as the explanatory model the simplest $\mathrm{NHC}, \mathbf{H}, \sigma_{\mathrm{p}}=$ $-295.9 \mathrm{ppm}$, with XX, YY and ZZ components equal to -255.5 , -533.6 and $-98.5 \mathrm{ppm}$, respectively (Table 1). Since $\sigma_{\mathrm{p}, \mathrm{YY}}$ is the main term, this entails that, under the action of an external magnetic field, MOs located on the $\mathrm{OX}$ and $\mathrm{OZ}$ axes will overlap after $90^{\circ}$ rotation. In this sense, the most representative MOs transition involves the occupied (occ.) $\mathrm{C}^{2}$ "lone pair" and the empty (or virtual) $\mathrm{p}_{z}$ orbital at $\mathrm{C}^{2}$. Only this overlap accounts for $-77.1 \mathrm{ppm}$ of the total $-533.6 \mathrm{ppm}$ calculated for $\sigma_{\mathrm{p}, \mathrm{YY}}$.

Although the $\sigma_{\mathrm{p}, \mathrm{YY}}$ component is the most important of the paramagnetic term of the shielding $(60 \%), \sigma_{\mathrm{p}, \mathrm{xx}}$ also exhibits a non-negligible contribution (29\%). In this regard, there are two most representative MOs transitions. The first involves a combination of the occupied $\mathrm{p}_{y}\left(\mathrm{C}^{2}\right)$ and $\mathrm{p}_{x}(\mathrm{~N})$ orbitals along 
a)

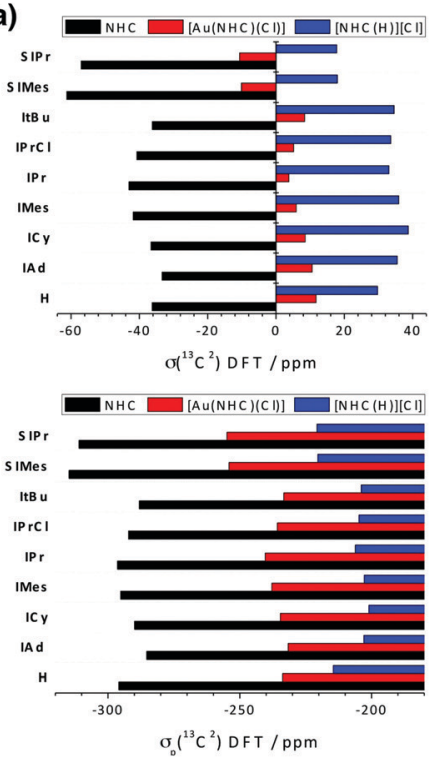

b)
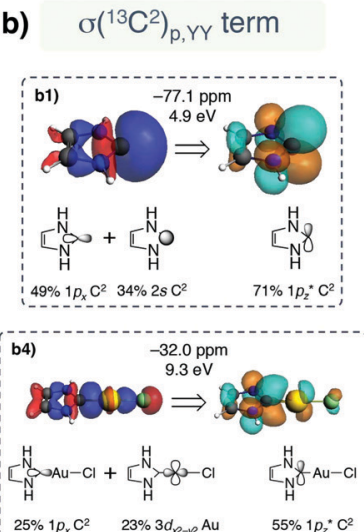

$25 \% 1 p_{x} \mathrm{C}^{2} \quad 23 \% 3 d_{x-12} \mathrm{Au} \quad 55 \% 1 p_{z}^{*} \mathrm{C}^{2}$

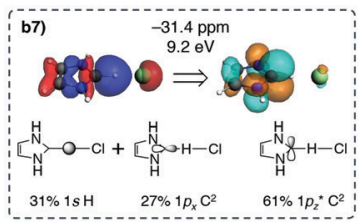

$\sigma\left({ }^{13} \mathrm{C}^{2}\right)_{p, \mathrm{Xx}}$ term
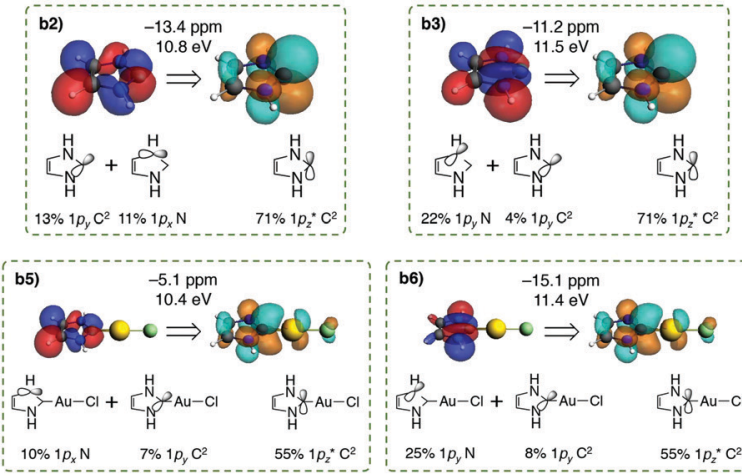

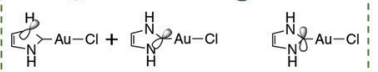

$25 \% 1 p_{y} \mathrm{~N} \quad 8 \% 1 p_{y} \mathrm{C}^{2} \quad 55 \% 1 p_{z}^{*} \mathrm{C}^{2}$
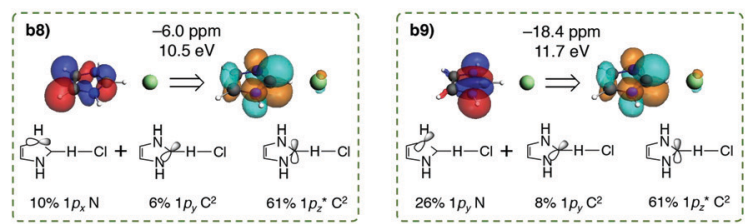

Fig. 3 (a) Calculated $\sigma\left({ }^{13} \mathrm{C}^{2}\right)$ and $\sigma_{\mathrm{p}}\left({ }^{13} \mathrm{C}^{2}\right)$, in ppm, for selected $\mathrm{NHC}$ (black) and $[\mathrm{Au}(\mathrm{NHC})(\mathrm{Cl})]$ (red) and $[\mathrm{NHC}(\mathrm{H})][\mathrm{Cl}]$ (blue) complexes. (b) Most representative MOs involved in the transition/overlapping for $\sigma_{\mathrm{p}, \mathrm{YY}}$ and $\sigma_{\mathrm{p}, \mathrm{XX}}$ contributions once an induced magnetic field is applied for $\mathrm{NHC}=\mathrm{H}$ and its respective $\mathrm{AuCl}$ and $\mathrm{HCl}$ moieties. (See axes orientation in Scheme 1).
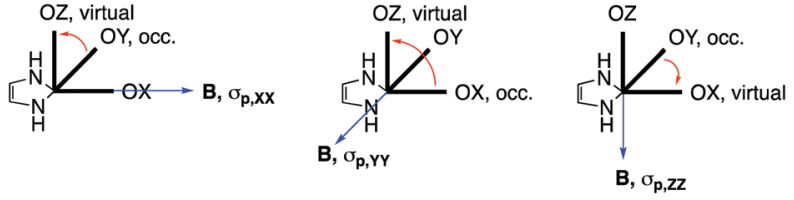

Scheme 1 Schematic orbital transitions/overlapping induced by the external magnetic field $(B)$ and nature of the $\sigma_{\mathrm{p}}$ contributions.

Table 1 Paramagnetic shielding values $\sigma_{\mathrm{p}}\left({ }^{13} \mathrm{C}^{2}\right)$ and their components for $\mathrm{NHC}=\mathbf{H}$ and respective $[\mathrm{Au}(\mathrm{NHC})(\mathrm{Cl})]$ and $[\mathrm{NHC}(\mathrm{H})][\mathrm{Cl}]$ adducts

\begin{tabular}{llll}
\hline & $\mathrm{NHC}$ & {$[\mathrm{Au}(\mathrm{NHC})(\mathrm{Cl})]$} & {$[\mathrm{NHC}(\mathrm{H})][\mathrm{Cl}]$} \\
\hline$\sigma_{\mathrm{p}}$ & -295.9 & -233.7 & -213.8 \\
$\sigma_{\mathrm{p}, \mathrm{XX}}$ & -255.5 & -243.9 & -255.5 \\
$\sigma_{\mathrm{p}, \mathrm{YY}}$ & -533.6 & -351.9 & -312.6 \\
$\sigma_{\mathrm{p}, \mathrm{ZZ}}$ & -98.5 & -105.4 & -73.4 \\
\hline
\end{tabular}

the $\mathrm{N}-\mathrm{C}$ bond and the empty $\mathrm{p}_{z}$ orbital at $\mathrm{C}^{2}(-13.4 \mathrm{ppm})$. The second involves a similar overlap but is comprised of the $\mathrm{p}_{y}(\mathrm{~N})$ and $\mathrm{p}_{y}\left(\mathrm{C}^{2}\right)$ for the occupied orbitals $(-11.2 \mathrm{ppm})$.

Once the NHC is bound to gold and proton, the $\mathrm{C}^{2}$ lone pair (lp) is no longer free but exerts its function as $\sigma$-donor. Both $[\mathrm{Au}(\mathrm{NHC})(\mathrm{Cl})]$ and $[\mathrm{NHC}(\mathrm{H})][\mathrm{Cl}]$ systems show very similar paramagnetic shielding values and behaviours of the most representative MOs involved in the analysis of the $\sigma_{\mathrm{p}, \mathrm{Xx}}$ and $\sigma_{\mathrm{p}, \mathrm{YY}}$ components (Fig. 3b). While in the free NHC case, the $\operatorname{lp}\left(\mathrm{C}^{2}\right) \rightarrow \mathrm{p}_{z}{ }^{*}\left(\mathrm{C}^{2}\right)$ overlap accounted in $-77.1 \mathrm{ppm}$ (b1), for NHC-gold(I) complexes and imidazolium compounds the $\sigma\left(\mathrm{C}^{2}-\mathrm{Au}\right) \rightarrow \mathrm{p}_{z}^{*}\left(\mathrm{C}^{2}\right)$ and $\sigma\left(\mathrm{C}^{2}-\mathrm{H}\right) \rightarrow$ $\mathrm{p}_{z}{ }^{*}\left(\mathrm{C}^{2}\right)$ overlap are $-32.0(\mathrm{~b} 2)$ and $-31.4(\mathrm{~b} 3) \mathrm{ppm}$, respectively.

The energy diagrams for the most representative MOs involved in the transition/overlapping of the $\sigma_{\mathrm{p}, \mathrm{YY}}$ and $\sigma_{\mathrm{p}, \mathrm{XX}}$ components are quite informative (Scheme 2). First, the occupied (coinciding with HOMO) $\mathrm{lp}\left(\mathrm{C}^{2}\right)$ orbital in NHC is strongly stabilised once complexed $(-5.1 \mathrm{eV}$ to -11.2 and $-11.4 \mathrm{eV})$. This is also seen for the empty $\mathrm{p}_{z}\left(\mathrm{C}^{2}\right)$ (coinciding with LUMO) orbital in NHC, although stabilisation takes place to a lesser extent $(-0.1 \mathrm{eV}$ to -1.9 and $-2.2 \mathrm{eV})$. As a result, while for $\sigma_{\mathrm{p}, \mathrm{YY}}$ the orbital energy difference $(\Delta \varepsilon)$ is $4.9 \mathrm{eV}$ in the free NHC, for $[\mathrm{Au}(\mathrm{NHC})(\mathrm{Cl})]$ and $[\mathrm{NHC}(\mathrm{H})][\mathrm{Cl}]$ this increases to 9.3 and $9.2 \mathrm{eV}$, in each case. This larger energy gap reinforces the upfield shielding for the carbene carbon atom once complex or when imidazolium formation occurs. In a similar fashion, both most representative occupied and empty MOs explaining $\sigma_{\mathrm{p}, \mathrm{xx}}$ are stabilised in the NHC-containing systems. However, since this stabilisation occurs to a similar extent (see Scheme 2), no significant differences are observed for $\Delta \varepsilon$.

With the objective of examining the nature of the $\mathrm{C}^{2}-\mathrm{Au}$ bond, we carried out EDA analysis for a series of nineteen $[\mathrm{Au}(\mathrm{NHC})(\mathrm{Cl})]$ complexes presented in Fig. 4 . These include some of the molecules previously analysed in Fig. 1 and some

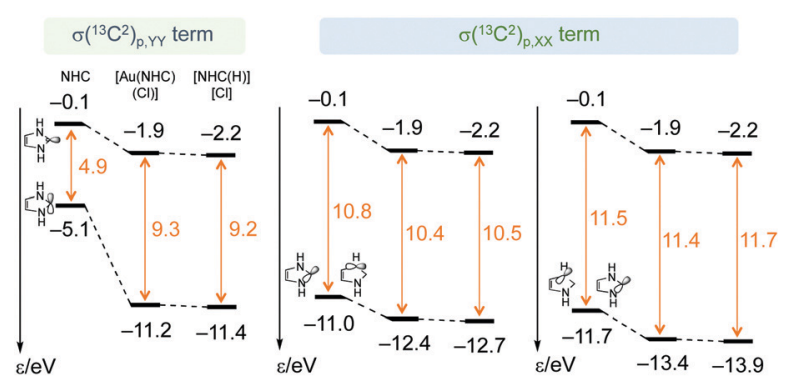

Scheme 2 Energy diagrams for most representative MOs involved in the transition/overlapping of $\sigma_{\mathrm{p}, Y Y}$ and $\sigma_{\mathrm{p}, \mathrm{Xx}}$ contributions shown in Fig. 3. 
related to our recent study dealing with the $\pi$-accepting abilities of NHCs in selenoureas. ${ }^{57}$

At first glance and from a Dewar-Chatt-Duncanson (DCD) perspective, ${ }^{58,59}[\mathrm{NHC}(\mathrm{H})][\mathrm{Cl}]$ compounds lack backdonation contributions in the $\mathrm{C}^{2}-\mathrm{H}$ bond. This is imposed by the fact that the proton has unoccupied orbitals, so the $\mathrm{C}^{2}-\mathrm{H}$ bond is solely maintained by $\sigma$-donation from NHC to the $\mathrm{HCl}$ moieties. Nonetheless, gold(I) contains a higher energy occupied d-type $\mathrm{MO}$ and it is capable of providing $\pi$-backdonation from $\mathrm{AuCl}$ to the NHC moieties.

Thus, in a "bond snapping energy" (BSE) ${ }^{60,61}$ context, binding energies for the heterolytic splitting of $[\mathrm{Au}(\mathrm{NHC})(\mathrm{Cl})]$ complexes into the two NHC and AuCl fragments diverge by $5.6 \mathrm{kcal} \mathrm{mol}^{-1}$ with minimum and maximum values of $-81.6\left(\mathbf{I}^{\mathbf{i}} \mathbf{P r}^{\mathbf{M e}}\right)$ and $-76.0\left(\mathbf{I P r}^{\mathbf{C l}}\right) \mathrm{kcal} \mathrm{mol}^{-1}$. Similarly, electronic interaction energies diverge by $4.2 \mathrm{kcal} \mathrm{mol}^{-1}$ with minimum and maximum values of -77.4 (IHept) and -73.2 (ICy) kcal mol ${ }^{-1}$ (see Table S4 for full energy details, $\left.\mathrm{ESI}^{\dagger}\right)$.

Complexes 1-19 in Fig. 4 were optimised by imposing $C_{\mathrm{s}}$ symmetry using the NHC plane (imidazolium ring of the NHC) as plane of symmetry. This conciliates that the electronic interaction energy, $E_{\text {int }}$, can be expressed as the sum of the contributions from respective orbital interactions within the various irreducible representations. For $C_{\mathrm{s}}$-symmetrised molecules, this involves that $E_{\text {int }}$ can be split into the $\sigma$ and $\pi$ contributions, corresponding to the $\mathrm{A}^{\prime}$ and $\mathrm{A}^{\prime \prime}$ irreducible representations, respectively: $E_{\text {int }}=E(\sigma)+E(\pi)$. As seen in Fig. $5 \mathrm{a}, E(\sigma)$ and $E(\pi)$ are estimated to be on average 81.1 and $18.9 \pm 1.1 \%$ for complexes 1-19, i.e., approximately $80 \%$ of the electronic interaction energy is due to orbital interactions of a $\sigma$ nature while $20 \%$ is due to the interaction between $\pi$ orbitals.

These interactions involve an occupied and a virtual (or unoccupied) orbital from the different NHC and AuCl fragments. Thus, through an Energy Decomposition Analysis (EDA), it is possible to estimate how much donation (from NHC to $\mathrm{AuCl}$ ) and backdonation (from $\mathrm{AuCl}$ to $\mathrm{NHC}$ ) takes place in the heterolytic splitting of $[\mathrm{Au}(\mathrm{NHC})(\mathrm{Cl})]$, and from these, how much is of a $\sigma$ and $\pi$ nature.
Fig. 5a indicates that $E(\sigma)$ is constituted of $c a .85 \%$ of $\sigma$-donation and $15 \%$ of $\sigma$-backdonation. In contrast, the backdonation term is notoriously superior than the donation for $E(\pi)$, i.e., $\pi$-backdonation is approximately $85 \%$. For the specific case of $[\mathrm{Au}(\mathbf{I P r})(\mathrm{Cl})](\mathbf{1})$, the $\mathrm{C}^{2}-\mathrm{Au}$ bond exhibits values of $-45.2 \mathrm{kcal} \mathrm{mol}^{-1}$ for $\sigma$-donation, and by -15.3 and $-15.1 \mathrm{kcal} \mathrm{mol}^{-1}$ for $\pi$ - and $\sigma$-backdonation, respectively. As an observation, the contribution made by the $\pi$-donation is quite minor, with values no larger than $-3 \mathrm{kcal} \mathrm{mol}^{-1}$. Despite $\sigma$-backdonation being a property generally ignored, our calculations suggest that this represents a significant energetic contribution to the stability of the $\mathrm{C}^{2}-\mathrm{Au}$ bond. As seen in Table S4 (ESI $\dagger$ ), this term is similar to the contributions from $\pi$-backdonation, offering a broader perspective of the bonding nature of NHC-metal complexes.

Along this line, Fig. 5b gathers those MOs that principally represent the classical DCD scheme. Using the simplest NHC of $\mathbf{H}$ as model, $\sigma$-donation in the $[\mathrm{Au}(\mathbf{H})(\mathrm{Cl})]$ complex mainly results from the combination between the occupied lone pair in $\mathrm{C}^{2}$ ( $\sigma$ symmetry) and the empty (or virtual) $\sigma^{*}$ orbital in $\mathrm{Au}$, which is $57 \% 2 \mathrm{~s}^{*}(\mathrm{Au})$ and $14 \% 2 \mathrm{p}^{*}(\mathrm{Au})$. Furthermore, the most representative MOs for $\pi$-backdonation are derived from the combination of the occupied $\mathrm{d}_{x z}$ orbital in Au and the empty $\mathrm{p}_{z}{ }^{*}$ orbital from $\mathrm{C}^{2}$. Although a significant amount of $\sigma$-backdonation has been accounted for in our NHC-gold(I) complexes, the assignment of the most representative MOs explaining this contribution is unclear. As indicated in Fig. 5b, the occupied $\mathrm{d}_{z^{2}}$ orbital in $\mathrm{Au}$ seems to be involved in such an interaction although with no welldefined empty orbital from the NHC fragment. This observation has been previously noted by Frison-Huynh ${ }^{62}$ and Hii $^{63}$ for NHCgold(I) and NHC-silver(I) complexes, respectively.

A recently report by Marchione et al., ${ }^{64}$ mentions that the $\sigma_{\mathrm{YY}}\left({ }_{13} \mathrm{C}^{2}\right)$ component of the shielding tensor correlates with $\sigma$-donation in a series of $[\mathrm{Au}(\mathrm{NHC})(\mathrm{X})]$ complexes, however, the NHC moiety ( $1 H$-imidazol-3-ium-2-ide) was common in all adducts. In our case, we present a series of $[\mathrm{Au}(\mathrm{NHC})(\mathrm{Cl})]$ adducts in which the NHC moiety varies. This reason ruled out the option of looking for correlations between quantities derived from EDA analysis vs. shielding for $\mathrm{C}^{2}, \sigma\left({ }^{13} \mathrm{C}^{2}\right)$. Instead,

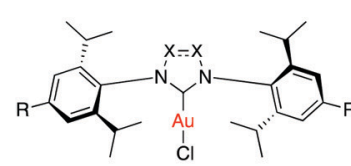

1, $\mathrm{IPr}, \mathrm{X}=\mathrm{CH}, \mathrm{R}=\mathrm{H}$

2, IPrOMe, $\mathrm{X}=\mathrm{CH}, \mathrm{R}=\mathrm{OMe}$

3, SIPr, $\mathrm{X}=\mathrm{CH}_{2}, \mathrm{R}=\mathrm{H}$

4, SIPrOMe, $\mathrm{X}=\mathrm{CH}_{2}, \mathrm{R}=\mathrm{OMe}$

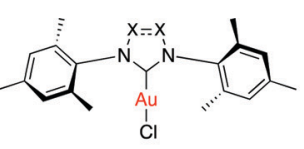

5, IMes, $\mathrm{X}=\mathrm{CH}$

6. Simes, $\mathrm{X}=\mathrm{CH}_{2}$

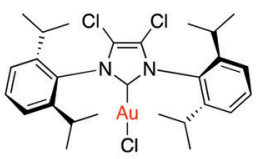

7, IPrCI

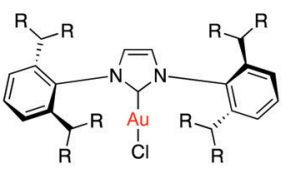

8, IMe, $\mathrm{R}=\mathrm{H}$

9, IPent, $\mathrm{R}=\mathrm{Et}$

10, INon, $\mathrm{R}={ }^{n} \mathrm{Pr}$

11, IHept, $\mathrm{R}={ }^{n} \mathrm{Bu}$
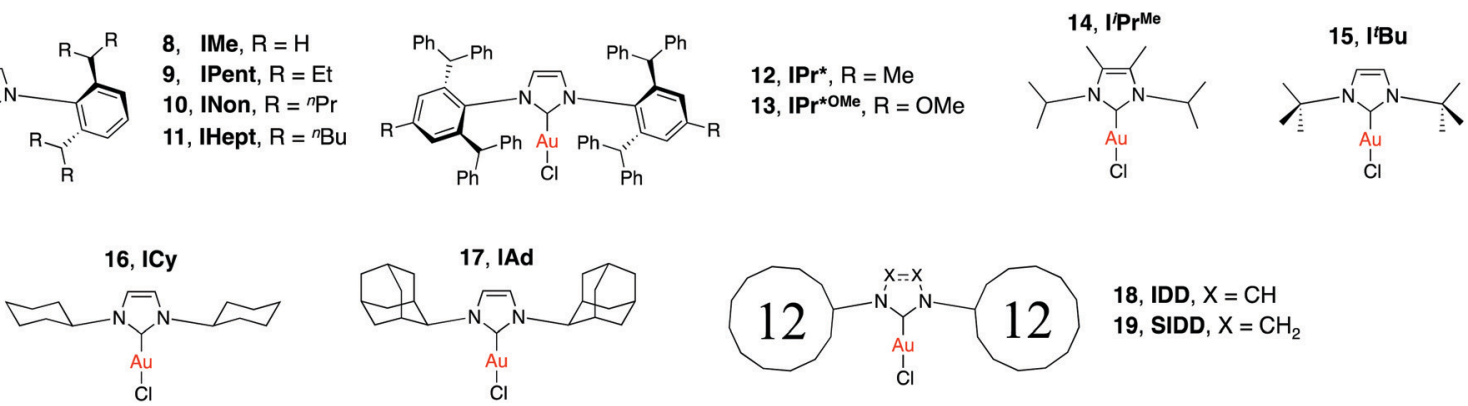

18, IDD, $\mathrm{X}=\mathrm{CH}$

19, SIDD, $\mathrm{X}=\mathrm{CH}_{2}$

Fig. 4 Selected $[\mathrm{Au}(\mathrm{NHC})(\mathrm{Cl})]$ complexes in which EDA analysis has been performed. 
a)

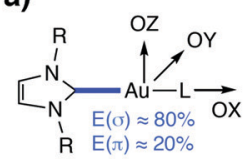

b)

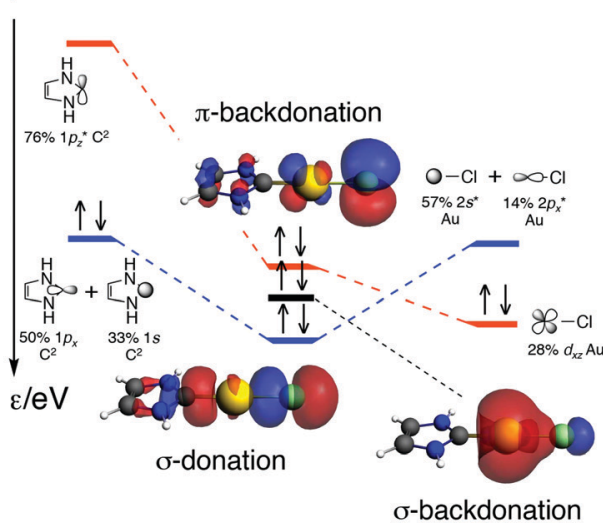

c)

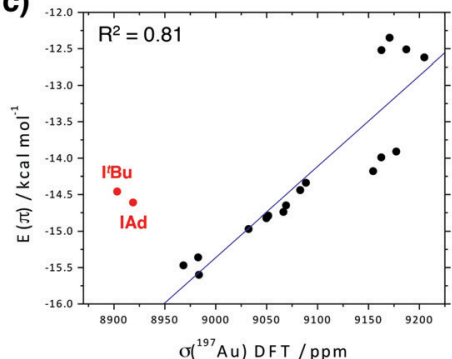

e)

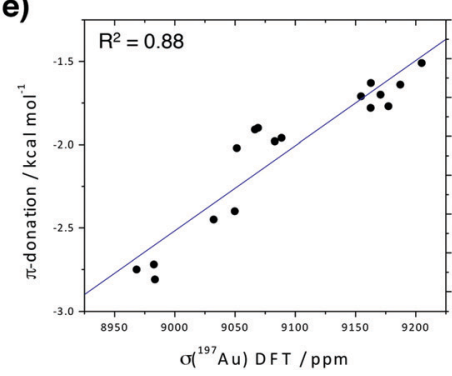

d)

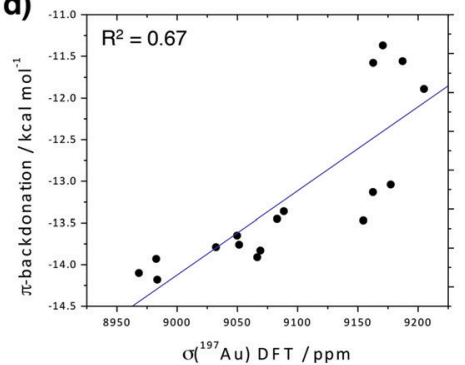

f)

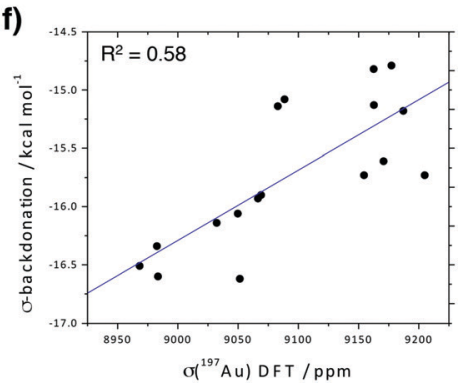

Fig. 5 (a) Contributions for $E(\sigma)$ and $E(\pi)$ and their donation and backdonation components in $[\mathrm{Au}(\mathrm{NHC})(\mathrm{Cl})]$ adducts. (b) Most representative MOs explaining $\sigma$-donation and $\pi$-backdonation. (c-f) Correlation plots between $E(\pi), \pi$-backdonation, $\pi$-donation and $\sigma$-backdonation $v s$. $\sigma\left({ }^{197} A u\right)$ shielding, respectively.

we report that there are several connections with the calculated $\sigma\left({ }^{197} \mathrm{Au}\right)$. Unfortunately, gold NMR is an extremely challenging technique due to the quadrupolar moment of the gold nuclei, and only a few examples have been reported in the literature using solid-state NMR spectroscopy. ${ }^{65}$ However, this is not a problem from an in silico perspective. Thus, in agreement with results by Belanzoni et al. ${ }^{33}$ Fig. $5 \mathrm{c}$ indicates that there is a direct correlation $\left(R^{2}=0.81\right)$ between the $\pi$-accepting ability of such complexes, measured as $E(\pi)$, and the calculated shielding for ${ }^{197} \mathrm{Au}$.

This finding describes a behaviour similar to what was recently described by us for $\mathrm{NHC}=$ Se selenoureas, ${ }^{57}$ including the two highly sterically demanding cases of $I^{t} \mathbf{B u}$ and IAd escaping from the main trend (and which has been removed from the statistical analysis). This correlation is also observed when accounting for the backdonation and donation components of $E(\pi)$, with coefficients of determination of 0.67 (Fig. $5 \mathrm{~d}$ ) and 0.88 (Fig. 5e), respectively. It is also understood that $\sigma\left({ }^{197} \mathrm{Au}\right)$ correlates with the $\sigma$-backdonation term $\left(R^{2}=0.58\right.$, Fig. $\left.5 f\right)$.

\section{Conclusions}

In summary, a set of NHCs and the isolobal complexes of NHCs with gold(I) and proton have been analysed by means of DFT calculations, comparing and rationalising their electronic properties, with special emphasis on NMR spectroscopy. Thus, shielding for the carbenic carbon atom, $\sigma\left({ }^{13} \mathrm{C}^{2}\right)$, is upfield in $[\mathrm{Au}(\mathrm{NHC})(\mathrm{Cl})]$ and $[\mathrm{NHC}(\mathrm{H})][\mathrm{Cl}]$ systems compared to the free NHCs. This has been calculated in an average of $c a .46 .6 \pm 2.2$ and $73.7 \pm 4.3$ $\mathrm{ppm}$, respectively, for the set studied. This tendency is also seen for the paramagnetic term of the magnetic shielding tensor with an average of $57.0 \pm 2.8$ and $88.0 \pm 4.5 \mathrm{ppm}$, in each case. The $\sigma_{\mathrm{p}}\left({ }^{13} \mathrm{C}^{2}\right)$, which depends on both occupied-occupied and occupied-virtual couplings between MOs induced by the external magnetic field, is the main shielding term which shows changes with variations in the NHC moiety. To explain why the $\sigma_{\mathrm{p}, \mathrm{YY}}$ component is the most affected once NHC is complexed with gold(I) and proton, it is clear that both occupied (coinciding with HOMO) and empty (coinciding with LUMO) $l p\left(\mathrm{C}^{2}\right)$ and $\mathrm{p}_{z}{ }^{*}\left(\mathrm{C}^{2}\right)$ orbitals in free NHCs are strongly stabilised in the $[\mathrm{Au}(\mathrm{NHC})(\mathrm{Cl})]$ complexes and isolobal $[\mathrm{NHC}(\mathrm{H})][\mathrm{Cl}]$ compounds, although stabilisation takes place to a lesser extent for the empty orbitals. As a result, for $\sigma_{\mathrm{p}, \mathrm{YY}}$ the orbital energy difference $(\Delta \varepsilon)$ is $4.9 \mathrm{eV}$ in the simplest NHC, $\mathbf{H}$, while for their complexes this increases to 9.3 and $9.2 \mathrm{eV}$, in each case. This larger energy gap reinforces the fact that shielding for carbene carbon atom is upfield once the formation of compounds occurs.

The absence of d-type orbitals in $\mathrm{H}^{+}$rules out $\pi$-backdonation in imidazolium C-H compounds. In contrast, $\mathrm{NHC}-$ gold(I) complexes exhibit important $\pi$-backdonation independently of how much $\sigma$-donation takes place between the NHC and gold(I)-X moieties, where $\mathrm{X}$ is an anionic ligand. In addition, we report that an important $\sigma$-backdonation component (a property generally ignored) contributes to the stabilisation of the $\mathrm{C}^{2}-\mathrm{Au}$ bond. We also report an unprecedented correlation between $E(\pi), \pi$-backdonation and $\pi$-donation contributions $v$ s. the calculated shielding for gold, $\sigma\left({ }^{197} \mathrm{Au}\right)$, providing a better understanding of the bond between gold and carbon.

\section{Conflicts of interest}

Authors declare no conflicts of interest.

\section{Acknowledgements}

L. M. A. is an ULPGC Postdoc Fellow, and thanks Universidad de Las Palmas de Gran Canaria (ULPGC). L. F., S. V. C. V., S. P. N. 
and L. C. acknowledge King Abdullah University of Science and Technology (KAUST) for support. R. M. P. V. and S. P. N. thank the European Research Council (ERC). A. P. is a Serra Húnter Fellow, and thanks the MICINN for the project PGC2018-097722B-I00. We also thank the KAUST Supercomputing Laboratory, housing the supercomputer Shaheen II, for providing computational resources.

\section{Notes and references}

1 A. J. Arduengo, R. L. Harlow and M. Kline, J. Am. Chem. Soc., 1991, 113, 361.

2 H.-W. Wanzlick and H.-J. Schönherr, Angew. Chem., Int. Ed. Engl., 1968, 7, 141.

3 K. Öfele, J. Organomet. Chem., 1968, 12, P42.

4 S. Díez-González and S. P. Nolan, Coord. Chem. Rev., 2007, 251, 874 .

5 C. Samojłowicz, M. Bieniek and K. Grela, Chem. Rev., 2009, 109, 3708.

6 L. Mercs and M. Albrecht, Chem. Soc. Rev., 2010, 39, 1903.

7 D. Janssen-Müller, C. Schlepphorst and F. Glorius, Chem. Soc. Rev., 2017, 46, 4845.

8 E. Peris, Chem. Rev., 2018, 118, 9988.

9 F. E. Hahn and M. C. Jahnke, Angew. Chem., Int. Ed., 2008, 47, 3122 .

10 H. G. Raubenheimer and S. Cronje, Chem. Soc. Rev., 2008, 37, 1998.

11 S. Díez-González, N. Marion and S. P. Nolan, Chem. Rev., 2009, 109, 3612.

12 S. P. Nolan, Acc. Chem. Res., 2011, 44, 91.

13 S. Bellemin-Laponnaz and S. Dagorne, Chem. Rev., 2014, $114,8747$.

14 M. N. Hopkinson, C. Richter, M. Schedler and F. Glorius, Nature, 2014, 510, 485.

15 V. Nesterov, D. Reiter, P. Bag, P. Frisch, R. Holzner, A. Porzelt and S. Inoue, Chem. Rev., 2018, 118, 9678.

16 G. Minghetti and F. Bonati, J. Organomet. Chem., 1973, 54, C62.

17 S. Dupuy and S. P. Nolan, Chem. - Eur. J., 2013, 19, 14034.

18 D. Gasperini, L. Maggi, S. Dupuy, R. M. P. Veenboer, D. B. Cordes, A. M. Z. Slawin and S. P. Nolan, Adv. Synth. Catal., 2016, 358, 3857.

19 Y. Oonishi, A. Gómez-Suárez, A. R. Martin and S. P. Nolan, Angew. Chem., Int. Ed., 2013, 52, 9767.

20 R. M. P. Veenboer, S. Dupuy and S. P. Nolan, ACS Catal., $2015,5,1330$.

21 A. Gómez-Herrera, F. Nahra, M. Brill, S. P. Nolan and C. S. J. Cazin, ChemCatChem, 2016, 8, 3381.

22 M. R. Fructos, M. Besora, A. A. C. Braga, M. M. DíazRequejo, F. Maseras and P. J. Pérez, Organometallics, 2017, 36, 172.

23 W. Walther, O. Dada, C. O’Beirne, I. Ott, G. Sánchez-Sanz, C. Schmidt, C. Werner, X. Zhu and M. Tacke, Lett. Drug Des. Discovery, 2017, 14, 125.
24 D. Curran, O. Dada, H. Müller-Bunz, M. Rothemund, G. Sánchez-Sanz, R. Schobert, X. Zhu and M. Tacke, Molecules, 2018, 23, 2031.

25 O. Dada, G. Sánchez-Sanz, M. Tacke and X. Zhu, Tetrahedron Lett., 2018, 59, 2904.

26 H. Jacobsen, A. Correa, A. Poater, C. Costabile and L. Cavallo, Coord. Chem. Rev., 2009, 253, 687.

27 H. Jacobsen, A. Correa, C. Costabile and L. Cavallo, J. Organomet. Chem., 2006, 691, 4350.

28 J. Nitsch, L. P. Wolters, C. Fonseca Guerra, F. M. Bickelhaupt and A. Steffen, Chem. - Eur. J., 2017, 23, 614.

29 S. Fantasia, J. L. Petersen, H. Jacobsen, L. Cavallo and S. P. Nolan, Organometallics, 2007, 26, 5880.

30 G. Ciancaleoni, N. Scafuri, G. Bistoni, A. Macchioni, F. Tarantelli, D. Zuccaccia and L. Belpassi, Inorg. Chem., 2014, 53, 9907.

31 O. Back, M. Henry-Ellinger, C. D. Martin, D. Martin and G. Bertrand, Angew. Chem., Int. Ed., 2013, 52, 2939.

32 A. Liske, K. Verlinden, H. Buhl, K. Schaper and C. Ganter, Organometallics, 2013, 32, 5269.

33 C. A. Gaggioli, G. Bistoni, G. Ciancaleoni, F. Tarantelli, L. Belpassi and P. Belanzoni, Chem. - Eur. J., 2017, 23, 7558.

34 A. D. Becke, Phys. Rev. A: At., Mol., Opt. Phys., 1988, 38, 3098.

35 J. P. Perdew, Phys. Rev. B: Condens. Matter Mater. Phys., 1986, 33, 8822.

36 E. Van Lenthe and E. J. Baerends, J. Comput. Chem., 2003, 24, 1142.

37 A. D. Becke, J. Chem. Phys., 1988, 88, 2547.

38 M. Franchini, P. H. T. Philipsen and L. Visscher, J. Comput. Chem., 2013, 34, 1819.

39 E. v. Lenthe, E. J. Baerends and J. G. Snijders, J. Chem. Phys., 1993, 99, 4597.

40 E. V. Lenthe, E. J. Baerends and J. G. Snijders, J. Chem. Phys., 1994, 101, 9783.

41 E. V. Lenthe, A. Ehlers and E.-J. Baerends, J. Chem. Phys., 1999, 110, 8943.

42 G. Schreckenbach and T. Ziegler, J. Phys. Chem., 1995, 99, 606.

43 G. Schreckenbach and T. Ziegler, Int. J. Quantum Chem., 1996, 60, 753.

44 G. Schreckenbach and T. Ziegler, Int. J. Quantum Chem., 1997, 61, 899.

45 S. K. Wolff and T. Ziegler, J. Chem. Phys., 1998, 109, 895.

46 M. P. Mitoraj, A. Michalak and T. Ziegler, J. Chem. Theory Comput., 2009, 5, 962.

47 M. V. Baker, P. J. Barnard, S. K. Brayshaw, J. L. Hickey, B. W. Skelton and A. H. White, Dalton Trans., 2005, 37, DOI: 10.1039/B412540A.

48 P. de Frémont, N. M. Scott, E. D. Stevens and S. P. Nolan, Organometallics, 2005, 24, 2411.

49 M. R. Fructos, T. R. Belderrain, P. de Frémont, N. M. Scott, S. P. Nolan, M. M. Díaz-Requejo and P. J. Pérez, Angew. Chem., Int. Ed., 2005, 44, 5284.

50 S. Gaillard, A. M. Z. Slawin and S. P. Nolan, Chem. Commun., 2010, 46, 2742.

51 S. Gaillard, A. M. Z. Slawin, A. T. Bonura, E. D. Stevens and S. P. Nolan, Organometallics, 2010, 29, 394. 
52 A. Gómez-Suárez, R. S. Ramón, O. Songis, A. M. Z. Slawin, C. S. J. Cazin and S. P. Nolan, Organometallics, 2011, 30, 5463.

53 A. Gómez-Suárez, R. S. Ramón, A. M. Z. Slawin and S. P. Nolan, Dalton Trans., 2012, 41, 5461.

54 D. Gasperini, A. Collado, A. Goméz-Suárez, D. B. Cordes, A. M. Z. Slawin and S. P. Nolan, Chem. - Eur. J., 2015, 21, 5403.

55 Y. Xu, X. Hu, S. Zhang, X. Xi and Y. Wu, ChemCatChem, 2016, 8, 262.

56 R. M. P. Veenboer, L. M. Azofra, D. Gasperini, A. Collado, D. B. Cordes, A. M. Z. Slawin, L. Cavallo and S. P. Nolan, Dalton Trans., 2019, 48, 7693.

57 S. V. C. Vummaleti, D. J. Nelson, A. Poater, A. Gómez-Suárez, D. B. Cordes, A. M. Z. Slawin, S. P. Nolan and L. Cavallo, Chem. Sci., 2015, 6, 1895.
58 J. Dewar, Bull. Soc. Chim. Fr., 1951, 18, C71.

59 J. Chatt and L. A. Duncanson, J. Chem. Soc., 1953, 2939, DOI: 10.1039/JR9530002939.

60 A. Poater, B. Cosenza, A. Correa, S. Giudice, F. Ragone, V. Scarano and L. Cavallo, Eur. J. Inorg. Chem., 2009, 1759.

61 H. Clavier and S. P. Nolan, Chem. Commun., 2010, 46, 841.

62 J. C. Bernhammer, G. Frison and H. V. Huynh, Chem. - Eur. J., 2013, 19, 12892.

63 V. H. L. Wong, A. J. P. White, T. S. A. Hor and K. K. Hii, Chem. Commun., 2015, 51, 17752.

64 D. Marchione, M. A. Izquierdo, G. Bistoni, R. W. A. Havenith, A. Macchioni, D. Zuccaccia, F. Tarantelli and L. Belpassi, Chem. - Eur. J., 2017, 23, 2722.

65 A. Narath, Phys. Rev., 1967, 163, 232. 